NASZA DERMATOLOGIA Online OUR DERMATOLOGY Online

Source of Support: Nil

Competing Interests: None declared

\section{A COMPARATIVE STUDY OF PSORIASIS AND PSORIASIFORM LESION ON BASIS OF CD4 AND CD8 CELL INFILTRATION}

\author{
Safia Rana ${ }^{1}$, Jairajpuri Shamim Zeeba ${ }^{1}$, Jetley Sujata ${ }^{1}$, \\ Kudesia Madhur ${ }^{2}$
}

${ }^{\prime}$ Department of Pathology, Hamdard Institute of Medical Sciences and Research, Jamia Hamdard, Hamdard Nagar, New Delhi, India

${ }^{2}$ Department of Pathology, Hindu Rao Hospital, New Delhi, India

Corresponding author: Ass. Prof. Jairajpuri Shamim Zeeba

zeebasj@rediffmail.com

\begin{abstract}
Introduction: Psoriasis is a chronic inflammatory skin disorder with immunological factors playing an important role in its pathogenesis. It is now regarded as a T cell mediated disorder in which lymphocytic infiltrates, mainly CD4 and CD 8 cells which provide a major contribution in the initiation and maintenance of psoriatic lesions.

Material and Methods: Skin biopsies from both psoriatic and psoriasiform lesions were stained with monoclonal antibodies against CD4 and CD8 and their percentage was calculated in the epidermis, upper dermis and lower dermis.

Results: The difference of mean value of percentage of CD4 cells, among psoriasis and psoriasiform lesion in the epidermis was statistically insignificant $(p=0.228)$, while it was significant in the upper dermis $(p=0.002)$ and in lower dermis $(p=0.043)$. The difference in the value of percentage of CD 8 cells was statistically significant in the epidermis $(\mathrm{p}=0.007)$, upper dermis $(\mathrm{p}=0.005)$, and the lower dermis $(\mathrm{p}=0.043)$. Conclusions: Both CD4 and CD 8 T cells are present in the appropriate anatomic locations to sustain lesional skin pathology in psoriasis and psoriasiform lesions.
\end{abstract}

Key words: psoriasis; psoriasiform; CD4; CD8

\section{Introduction}

Psoriasis is a chronic, non-pruritic disease characterised by erythematous plaques, covered by fine silvery scales. It is a common chronic inflammatory skin disorder affecting approximately $1.5-2 \%$ of the population in western countries and $1.3 \%$ in general population [1]. Typically it involves extensor surfaces such as elbows, knees, back and scalp [2]. Histologically it is characterised by confluent parakeratosis,acanthosis with regular elongation of rete ridges, suprapapillary thinning, presence of spongiform pustules, diminished to absent granular layer and presence of Munro microabcesses. Dermis on the other hand shows elongation and edema of dermal papillae alongwith presence of dilated and tortuous capillaries.

Psoriasis is an autoimmune skin disease characterised by T-cell mediated hyperproliferation of keratinocytes. Immunological factors are known to play an important role in the pathogenesis of psoriasis. It is now regarded to be a
T-cell mediated disorder with T-lymphocyte predominance in the inflammatory infiltrates, mainly CD4+ (helper/ inducer) lymphocytes alongwith CD8+ (suppressor/ cytotoxic) subsets are known to occur [3,4]. T-lymphocytes in psoriatic lesion are known to be in an activated state with expression of HLA-DR and IL-2 receptor. Pathologic collaboration between innate immunity (mediated by antigen presenting cells and NK-T lymphocytes) and acquired immunity (mediated by T-lymphocytes) results in production of cytokines, chemokines and growth factors that contribute to inflammatory infiltrate seen in psoriatic plaques $[3,4]$. CD4+ T-cells are important in initiating and maintaining the pathogenic process of psoriasis but that cross-primed CD8+ T-cells are the main effector cells [5].

The presence and potential importance of T-cells in the epidermis was emphasized in the pathogenesis of psoriasis. Mixtures of CD4+ T-cells and CD 8+ T-cells were found in papillary dermis and epidermis of psoriatic lesion [6]. 
More so, it has been suggested that spontaneous remission or fluctuation in the activity of disease is determined by balance within the lesion between effector and suppressor, CD4+ and CD8+ T-cells respectively.

Psoriasiform lesions on the otherhand have clinical and histological features similar to psoriasis (Fig. 1). Allergic contact dermatitis, seborrhoeic dermatitis, Atopic dermatitis, Pityriasis rubra, Lichen simplex chronicus are considered as psoriasiform lesions. T-cell play a role in the pathogenesis of psoriasiform lesions more so in atopic dermatitis. Studies have reported a high proportion of CD4+ T-cells in the dermis on immunohistochemical analysis [7].

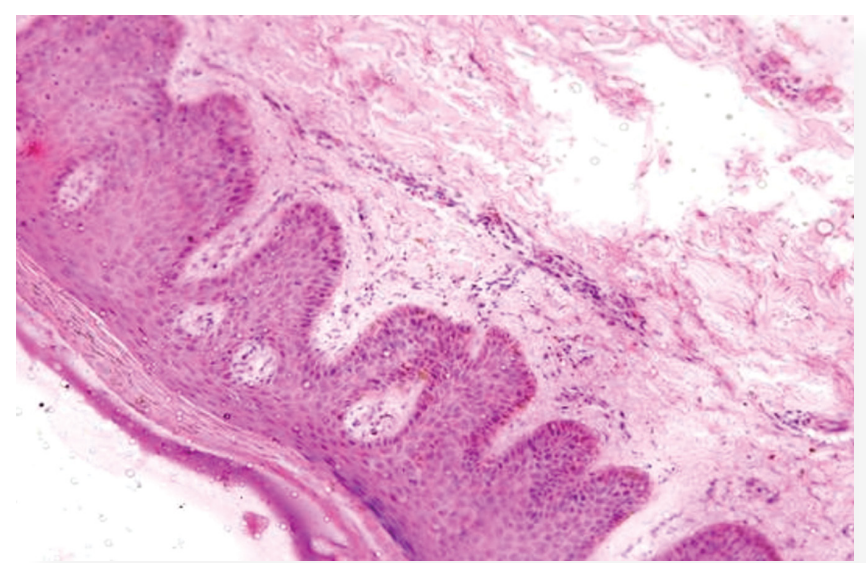

Figure 1. Microphotograph showing hyperkeratosis, parakeratosis and irregular acanthosis in psoriasiform dermatitis (20X, H\&E)

The presentation in inflammatory cells in the skin is exceedingly heterogenous. By means of potent antigen presenting cells, cytokines and chemokines, lymphocytes, the skin is able to respond very efficiently to pathogens that threaten the individual. T-cell infiltration in psoriasis has recently been an important subject of investigation. Comparative analysis of lesional T- cell infiltrate in psoriasis and psoriasiform dermatitis has only been sparingly performed. Our study aimed at evaluating and comparing CD4 and CD8 cell distribution in psoriasis and psorisiform lesions.

\section{Material and Methods}

Skin biopsies from 25 cases each of psoriasis and psoriasiform lesions were included in the present study. The diagnosis of psoriasis was confirmed on the basis of clinical features (pink to red papules with fine silvery scales and positive Auspitz sign) in conjunction with classical histological changes. The psoriasiform lesions included in our study were endogenous eczema, hyperkeratotic eczema, seborrhoeic dermatitis, nummular eczema, allergic contact dermatitis, irritant contact dermatitis, Lichen simplex chronicus and pityriasis rosea.

The biopsies obtained were processed, sections cut and stained with Haematoxylin \& Eosin (H\&E).Stained sections were examined under light microscope for histopathological characterization of the lesion. The epidermis, upper dermis and lower dermis were examined for the presence of inflammatory infiltrate, the nature of infiltrate was categorised as neutrophils or lymphocytes. It was graded as: 0-no infiltrate, 1-mild infiltrate, 2-moderate infiltrate, 3-marked infiltrate.
Sections were obtained and immunohistochemical staining for CD 4 and CD 8, (Bio Genex, USA) using the streptavidin biotin peroxidise method was performed. Simultaneously, CD4 and CD8 stained sections were examined and their percentage was determined among the lymphoid cells in epidermis, upper dermis and lower dermis. Statistical analysis was done. The data of grading of inflammation was categorical in nature, hence chi-square test was applied to study the difference between psoriasis and psoriasiform lesion. The data of CD4 and CD8 T-cell distribution was normally distributed, hence students t-test was applied to study the difference. A $p$ value of $p<0.05$ was considered statistically significant.

\section{Results}

Grades of inflammation were assesed in both psoriasis and psoriasiform lesions on the H\&E stained sections and results are as in Table I. The inflammation in the epidermis was present in 11 cases $(44 \%)$ of psoriasis and all were of mild grade comprising of mixtures of polymorphs and lymphocytes. The mean of the percentage of polymorphs was calculated out of total inflammatory cells and among the positive cases, it was $67 \%(\mathrm{SD}=16)$, whereas that of lymphocytes was $33 \%(\mathrm{SD}=16)$. In the upper dermis (upper dermis), inflammation was evident in all the 25 cases $(100 \%)$ and it was mostly of moderate grade. Polymorphs were seen in 21 cases $(84 \%)$ with a mean percentage of $23 \%$ $(\mathrm{SD}=15.22)$ and lymphocytes in all the 25 cases $(100 \%)$ had a mean of $83 \%(\mathrm{SD}=16.4)$.

Inflammation in the lower (reticular) dermis was present in 18 cases, (72\%) mostly of mild grade, with polymorphs in only 3 cases $(12 \%)$ and the mean among positive cases was $23 \%(\mathrm{SD}=23.10)$ while lymphocytes were evident in 18 cases $(72 \%)$ with amean value of percentage of cells as $96 \%(\mathrm{SD}=11.95)$. None of the case showed presence of only polymorphs. Polymorphs if seen in cases of psoriasis were associated with lymphocytes (Tabl. I).

In psoriasiform lesions the inflammation was present in the epidermis in only 2 cases ( $8 \%$ ), both showing mixtures of polymorphs and lymphocytes. Mean value of percentage of polymorphs in positive cases was $50 \%(\mathrm{SD}=0)$ whereas that of lymphocytes was $50 \%(\mathrm{SD}=0)$. Within the upper dermis, all the 25 cases $(100 \%)$ showed inflammation with grade 2 inflammation in maximum number of cases. In 22 cases $(88 \%)$, polymorphs were seen with a mean value of cells in positive cases as $26.36 \%(\mathrm{SD}=17.54)$, lymphocytes in all the cases $(100 \%)$, mean $76.80 \%(S . D=18.59)$. Only four cases $(16 \%)$ in the lower dermis showed inflammation, three having mild and one severe inflammation. One case (4\%) had polymorphs with a mean value of $30 \%$ while 4 cases $(16 \%)$ had lymphocytes with a mean value of percentage of cells as $92.50 \%$ (S.D=15.0) (Tabl. I).

Immunohistochemical staining was done and the distribution of CD4 positive cells was seen in psoriasis patients. In the epidermis only 5 cases $(20 \%)$ were positive and the mean value of percentage of cells in the positive cases was $30 \%$ $(\mathrm{SD}=20)$. In the upper dermis, CD 4 cells were present in 23 cases $(92 \%)$ with a mean value of $35 \%$ in positive cases $(\mathrm{SD}=21.24)$ (Fig. 2). In the lower dermis, 11 cases $(44 \%)$ were positive for $\mathrm{CD} 4$ cells with mean of $34 \%(\mathrm{SD}=24.47)$ (Tabl. II). 
CD 8 positive cells on the other hand were seen in the epidermis in 10 cases $(40 \%)$ and the mean among positive cases was $82 \%(\mathrm{SD}=21.50)$. In the upper dermis, all the 25 cases showed CD 8 positive cells with mean value of $65 \%$
$(\mathrm{SD}=21.70)$ (Fig. 3). In the lower dermis, $\mathrm{CD} 8$ positive cells were found in 17 cases $(68 \%)$ with a mean value of $75 \%$ $(\mathrm{SD}=26.66)$ (Tabl. III), (Fig. 4).

\begin{tabular}{|c|c|c|c|c|c|c|}
\hline Grade & \multicolumn{2}{|c|}{ Epidermis } & \multicolumn{2}{c|}{ Upper Dermis } & \multicolumn{2}{c|}{ Lower Dermis } \\
\hline & Psoriasis & $\begin{array}{l}\text { Psoriasi- } \\
\text { form }\end{array}$ & Psoriasis & $\begin{array}{l}\text { Psoriasi- } \\
\text { form }\end{array}$ & Psoriasis & $\begin{array}{l}\text { Psoriasi- } \\
\text { form }\end{array}$ \\
\hline 0 (nil) & 14 & 23 & 0 & 0 & 7 & 21 \\
\hline 1 (mild) & 11 & 2 & 2 & 8 & 13 & 3 \\
\hline 2 (moderate) & 0 & 0 & 15 & 15 & 5 & 0 \\
\hline 3 (severe) & 0 & 0 & 8 & 2 & 0 & 1 \\
\hline
\end{tabular}

Table I. Grades of inflammation in psoriasis and psoriasiform cases

\begin{tabular}{|c|c|c|c|c|c|c|}
\hline $\begin{array}{c}\text { \% of CD 4 } \\
\text { positive cells }\end{array}$ & \multicolumn{2}{c|}{$\begin{array}{c}\text { Epidermis } \\
\text { (No. of cases) }\end{array}$} & \multicolumn{2}{c|}{$\begin{array}{c}\text { Upper Dermis } \\
\text { (No. of cases) }\end{array}$} & \multicolumn{2}{c|}{$\begin{array}{c}\text { Lower Dermis } \\
\text { (No. of cases) }\end{array}$} \\
\hline & Psoriasis & $\begin{array}{l}\text { Psoriasi- } \\
\text { form }\end{array}$ & Psoriasis & $\begin{array}{l}\text { Psoriasi- } \\
\text { form }\end{array}$ & Psoriasis & $\begin{array}{l}\text { Psoriasi- } \\
\text { form }\end{array}$ \\
\hline 0 & 20 & 23 & 3 & 1 & 14 & 21 \\
\hline $1-10$ & 2 & 1 & 6 & 1 & 3 & 2 \\
\hline $11-20$ & 0 & 0 & 3 & 3 & 1 & 0 \\
\hline $21-30$ & 1 & 0 & 4 & 0 & 2 & 0 \\
\hline $31-40$ & 0 & 0 & 1 & 2 & 1 & 0 \\
\hline $41-50$ & 2 & 1 & 3 & 3 & 2 & 0 \\
\hline $51-60$ & 0 & 0 & 3 & 5 & 0 & 0 \\
\hline $61-70$ & 0 & 0 & 1 & 5 & 0 & 0 \\
\hline $71-80$ & 0 & 0 & 1 & 1 & 0 & 2 \\
\hline $81-90$ & 0 & 0 & 0 & 4 & 2 & 0 \\
\hline $91-100$ & 0 & 0 & 0 & 0 & 0 & 0 \\
\hline
\end{tabular}

Table II. Comparison of distribution of CD4 positive cells in psoriasis and psoriasiform cases

\begin{tabular}{|c|c|c|c|c|c|c|}
\hline $\begin{array}{c}\text { \% of positive } \\
\text { CD8 cells }\end{array}$ & \multicolumn{2}{c|}{$\begin{array}{c}\text { Epidermis } \\
\text { (No. of cases) }\end{array}$} & \multicolumn{2}{c|}{$\begin{array}{c}\text { Upper Dermis } \\
\text { (No. of cases) }\end{array}$} & \multicolumn{2}{c|}{$\begin{array}{c}\text { Lower Dermis } \\
\text { (No. of cases) }\end{array}$} \\
\hline & Psoriasis & $\begin{array}{l}\text { Psoriasi- } \\
\text { form }\end{array}$ & Psoriasis & $\begin{array}{l}\text { Psoriasi- } \\
\text { form }\end{array}$ & Psoriasis & $\begin{array}{l}\text { Psoriasi- } \\
\text { form }\end{array}$ \\
\hline 0 & 15 & 23 & 0 & 0 & 8 & 21 \\
\hline $1-10$ & 0 & 0 & 0 & 4 & 1 & 0 \\
\hline $11-20$ & 0 & 0 & 2 & 1 & 0 & 2 \\
\hline $21-30$ & 0 & 0 & 0 & 5 & 0 & 0 \\
\hline $31-40$ & 0 & 0 & 3 & 5 & 0 & 0 \\
\hline $41-50$ & 2 & 1 & 3 & 3 & 4 & 0 \\
\hline $51-60$ & 1 & 0 & 2 & 2 & 1 & 0 \\
\hline $61-70$ & 0 & 0 & 6 & 0 & 1 & 0 \\
\hline $71-80$ & 2 & 0 & 5 & 3 & 2 & 0 \\
\hline $81-90$ & 0 & 1 & 2 & 1 & 1 & 2 \\
\hline $91-100$ & 5 & 0 & 2 & 1 & 7 & 0 \\
\hline
\end{tabular}

Table III. Comparison of distribution of CD8 positive cells in psoriasis and psoriasiform cases 


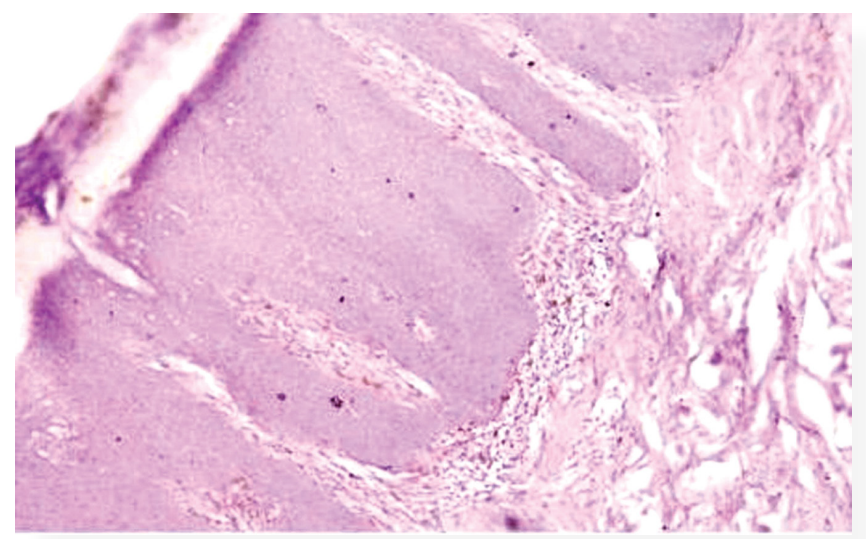

Figure 2. Microphotograph showing CD4+ T-cell in upper dermis of psoriasis case (20X, IHC)

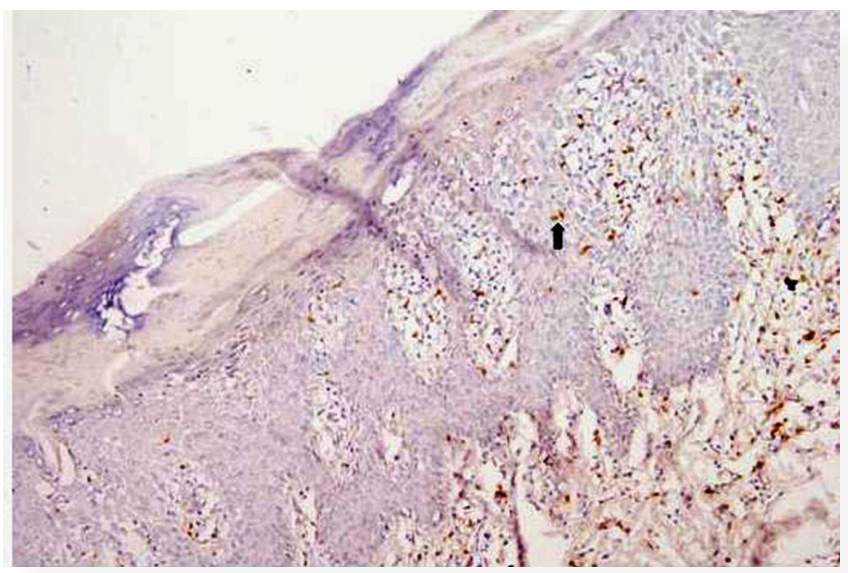

Figure 4. Microphotograph showing perivascular presence of CD8 +T-cells in deep dermis of psoriasis (20X, IHC)

On evaluating Psoriasiform lesions only 2 cases (8\%) showed CD4 positivity in the epidermis of psoriasiform lesion. The mean value of percentage of cells was $30 \%$ of these positive cases $(\mathrm{SD}=28.28)$. In the upper dermis area, 24 cases $(96 \%)$ showed positivity with a mean value of $55.6 \%$ $(\mathrm{SD}=25.8)$. In the lower dermis area, only four cases $(16 \%)$ showed CD4 positivity with a mean value of $45 \%(\mathrm{SD}=40.4)$ (Tabl. II). CD 8 positive cells in the epidermis were seen in 2 cases $(8 \%)$ and the mean value among positive cases was $70 \%(\mathrm{SD}=28.24)$. In the upper dermis area, all the 25 cases showed CD8 cells with a mean value of $44.4(\mathrm{SD}=25.8)$ (Fig. $5)$. Lower dermis region showed CD8 cells in 4 cases $(16 \%)$ with a mean value of percentage of infiltrating cells as $55 \%$ $(\mathrm{SD}=40.4)$ (Tabl. III).

On comparing CD4 and CD8 cells infiltration in psoriasis and psoriasiform lesions, the difference in percentage of CD4+ T-cells in epidermis was not statistically significant $(\mathrm{p}=0.228$, student $\mathrm{t}$-test $)$ between psoriasis and psoriasiform lesion. However, the difference in percentage of CD8 positive T-cells in epidermis between psoriasis and psorisiform lesion was statistically significant $(\mathrm{p}=0.007)$. There were more number of CD $8+$ T-cells.

On analyzing the upper dermis for CD4 and CD8, the difference in percentage of CD4+ T-cells was statistically significant $(p=0.002)$ between psoriasis and psoriasiform lesion. More so, the difference in percentage of CD8+ $\mathrm{T}$-cells, in upper dermis between psoriasis and psoriasiform lesion was also statistically significant $(\mathrm{p}=0.005)$.

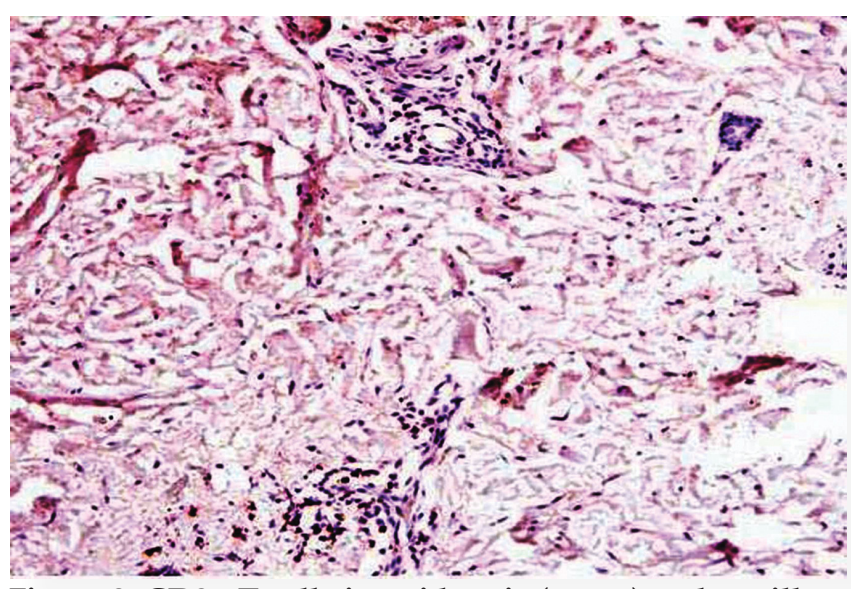

Figure 3. CD8+ T-cells in epidermis (arrow) and papillary dermis of psoriasis (20X, IHC)

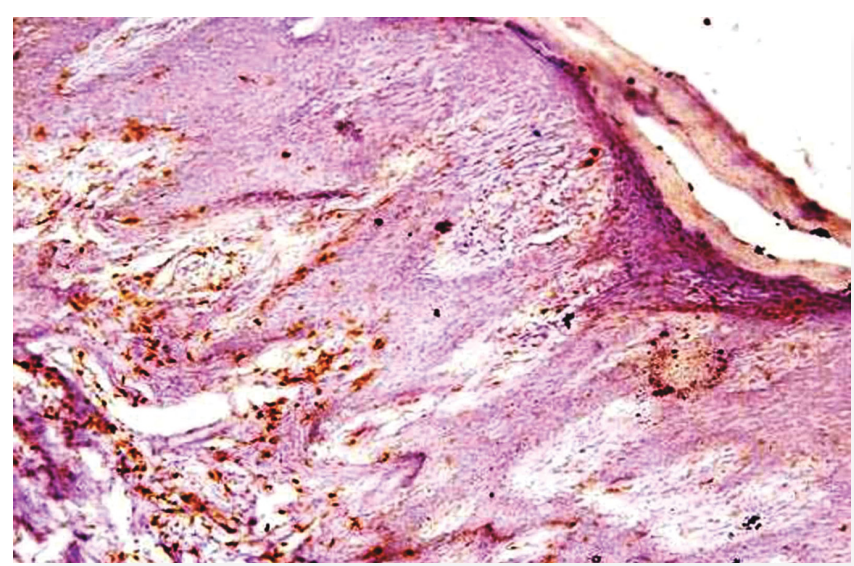

Figure 5. Microphotograph showing CD $8+$ T-cells in upper dermis of psoriasiform case (20X, IHC)

A statistically significant difference was drawn in percentage of CD4+ $(p=0.043)$ and CD8+ $(p=0.000)$ T-cells in lower dermis of psoriasis and psoriasiform lesion.

\section{Discussion}

Psoriasis is a chronic inflammatory relapsing disorder accompanied by an infiltration of activated T-cells. The presence and potential functional importance of these cells in the pathogenesis of psoriasis is emphasized [6]. An inflammatory infiltrate consisting mostly of lymphocytes is present in the upper dermis and the papillae [8], however in early lesions neutrophils may be seen. The expression of CD4+ lymphocytes as well as CD8 lymphocytes is increased significantly in the epidermis and the dermis of lesional skin as compared to healthy skin. This suggested that a cascade of cells and cytokines play an important role in the immunopathogenesis of psoriasis vulgaris [9]. Psoriasis is characterised by increased proliferative activity of normal slowly cycling epidermal progenitors that is followed by chronic accumulation of immunocompetent cells [10].

Normal skin lacks interferon $\Upsilon$ (IF- $\Upsilon$ ) [11]. In lesional skin, however T-cell clones produce IF- $\Upsilon$, an important element for induction into the G1phase of cell cycle by psoriatic keratinocyte stem cells leading to hyperproliferation of $\mathrm{T}$-cell clones of psoriatic origin release IFN- $\Upsilon$ in vitro which together with growth factors (IL3, GM-CSF) [12] and fibronectin are necessary for cell cycle induction occurring in vivo among K1/K10 keratinocyte stem cells. 
A study revealed elevated levels of CD4 and CD8+ T-cells in all compartments of psoriatic skin as compared to normal indicating both CD4 and CD8+ IF- $\Upsilon+$ T-cells are present in appropriate anatomic locations in order to sustain lesional pathology [13]. Similarly, in the present study, inflammation was seen in all the compartments of lesional skin, it was of mild grade in the epidermis of $44 \%$ cases, while in upper dermis $100 \%$ of cases showed moderate grade and in the lower dermis, $72 \%$ cases had inflammation of mild grade.

$\mathrm{T}$ cell infiltration in psoriasis has recently been an important subject of investigation. Comparative analysis of lesional T-cell infiltrate in psoriasis and other psoriasiform dermatitis have been only sparingly performed [14]. Psoriasis is accompanied by an infiltration of activated T-cells in papillary dermis and epidermis. The presence of potential functional importance of T-cells was emphasised in the pathogenesis of psoriasis [6]. In the present study, CD8+ T-cells were present in the epidermis of $40 \%$ cases with a mean value of $82 \%$. This is in concordance with previous studies $[5,6,15,16]$ indicating CD8 + T-cells play a major effector role in psoriasis. CD8 T-cells are known to respond to specific antigens in the psoriatic lesions with help of CD4 T-cells that are also probably antigen specific [17].

Most studies emphasize the role of CD4 and CD8 cells in the pathogenesis of psoriasis $[5,6,18,14]$. CD4+ T-cells may be necessary for providing critical inductive and helper signals while CD8 are likely to be the principal effector agents in psoriasis. It should be reiterated that at least $80 \%$ of T-cell in chronic lesional epidermis are of CD8 phenotype associated with keratinocyte. Furthermore an increase in CD8 T-cells has been observed in the epidermis of uninvolved skin of psoriasis patients [19]. We found CD8+ cells in upper dermis in all the biopsies $(100 \%)$ and CD4+ cells in most of the biopsies (88\%). More number of CD8+ cells were reported as compared to CD4+ cells in upper dermis in the present study. This was in contrast to trends reported in literature where a higher percentage of CD4+ cells as compared to CD8+ cells have been observed in the upper dermis $[5,15]$ alongwith mixtures of CD4+ and CD8+ cells [6]. However, it compared favourably with others, where CD8+ T-cells were distributed both in the epidermis and dermis but preferentially in the dermis, as seen in the present study [20]. On review of literature, no relevant data was available to the best of our knowledge which described percentage of CD4 and CD8+ cells in papillary and reticular dermis separately of psoriatic lesions. However, in our study, the percentage of CD4+ cells increased in lower dermis as compared to upper dermis. In the lower dermis region, 11 cases (44\%) were positive for CD4 cells. CD8+ cells were found in 17 cases $(68 \%)$. CD8+ cells secrete various cytokines affecting the epidermis and is also stimulated by cytokines secreted by epidermal, dendritic cells as well as CD4+ cells. Studies investigating the pathogenesis of psoriasis conclude the essential role of CD8+ cells in psoriasis [5,6,14,18,21,22]. $\mathrm{T}$ lymphocytes in lesional skin showed CD8+ cell figured more strongly than $\mathrm{C}$ cells [23].

Psoriasiform lesions on the other hand have morphological features similar to psoriasis. They are inflammatory diseases characterized by infiltration of lymphocytes and macrophages Allergic contact dermatitis, seborrhoeic dermatitis, Atopic dermatitis, Pityriasis rubra, Lichen simplex chronicus are considered as psoriasiform lesions. T-cell are known to play a role in the pathogenesis of psoriasiform lesions more so in atopic dermatitis. Studies have reported a high proportion of CD4+ T-cells in the dermis on immunohistochemical analysis [7]. An immunophenotyping of the inflammation of psoriasiform lesions was done in our study, CD4+ cells were seen predominantly in the upper dermis, $96 \%$ cases had CD4+ T-cells with a mean of 56.25\%. Lower dermis area showed $16 \%$ cases having CD4+ cells with a mean of $55 \%$. Psorisiform lesion such as atopic dermatitis is a multifactorial chronic inflammatory skin disease where CD4+ cells are considered to play an important role in its pathogenesis [24]. In a study, the patch test positive atopic dermatitis patients showed an infiltration of CD4+ T-cells. About $10 \%$ of the cells were CD8 positive ranging from $3-24 \%$ $[24,25]$. Immunophenotyping of the inflammatory cells performed in atopic dermatitis in other studies reveal a high proportion of CD4+ T-cells in dermis as well as in peripheral blood lymphocyte showing selective activation of CD4+ lymphocytes and a relative expansion of CD4+ cell subset [26,27].

Exact etiology of Pityriasis rosea, another psoriasiform lesion is still unknown. Cell mediated immunity may be involved in the pathogenesis [28] as activated helperinducer T-lymphocyte (CD4+/HLA-DR+) are present in the epidermis and dermis. In our series of Pityriasis rosea, in the upper dermis area, 90\% of the inflammatory cells were of CD4 and 10\% were of CD8 type. Allergic contact dermatitis. represents a type IV cell mediated delayed type of hyper sensitivity reaction. Both CD4 and CD8+ T-lymphocytes participate in contact hypersensitivity reaction [22].

On comparing the immunophenotypic pattern between psoriasis and psoriasiform group CD4+ T-cells in the epidermis were evident in only 5 cases of psoriasis and in two cases among the psoriasiform group in our study which was statistically insignificant $(p=0.228)$. Various studies, have shown that CD4+ cells are less frequent in psoriatic epidermis $[5,6,14,18]$. Moreso, CD8+ cells were seen in epidermis in $40 \%$ cases in psoriasis and $8 \%$ in psoriasiform lesions. The mean value of percentage of cells was $82 \%$ in psoriasis and $70 \%$ in psoriasiform group and this difference was statistically significant $(\mathrm{p}=0.007)$. These findings are in concordance with earlier studies which have shown CD8+ cells in abundance in psoriasis [5,6,14,18,27].

In the upper dermis positivity of CD4+ T-cells were found to be similar in both psoriasis and psoriasiform lesions in the present study. The mean value of percentage of cells was $35 \%$ in psoriasis and $55.6 \%$ among psoriasiform lesion and this difference was statistically significant $(p=0.002)$. The CD8+ T-cells in this area were found to be similar in both psoriasis and psoriasiform cases. All the cases in both the groups were positive for CD8. The mean value of percentage of CD8+ T-cells among psoriasis cases was $75 \%$ while in psoriasiform group, it was $44.4 \%$, a statistically significant $(\mathrm{p}=0.005)$ difference was drawn. In the upper dermis area, a slightly higher number of CD4+ cells as compared to CD8+ T-cells which were more sporadic in dermis in psoriatic $[5,14]$. One of the study [6] has shown mixtures of CD4+ and CD8+ T-cells were present in the upper dermis in psoriasis whereas studies done for psoriasiform group show that CD4 + cells are in abundance in the upper dermis area and play a major role in the pathogenesis $[24,25,27,28]$. 
On comparing the infiltration of the lower dermis by CD4+ $T$ cells, a statistically significant difference $(p=0.043)$ in the mean value of percentage of cells was seen between psoriasis and psoriasiform lesions. On the other hand,a statistically significant difference $(p=0.000)$ was also drawn on the mean value of CD8+ T-cells present in the lower dermis. No relevant data to the best of our knowledge was available on the distribution of CD4+ and CD8+ T- cells in papillary and reticular dermis separately.

\section{Conclusion}

The histopathological features of psoriasis have many similarities with other psoriasiform lesions which cause diagnostic difficulties in acheiving a final diagnosis. Distinguishing the two lesions on the basis of immunophenotyping of T-cell infiltrate has emerged as a useful tool. We demonstrated a statistically significant difference in grades of inflammation between psoriasis and psoriasiform lesion. A statistically significant difference has been drawn in CD4 and CD8 T-cell infiltration in upper and lower dermis, and CD8 in epidermis however the difference was insignificant for CD4 cells in the epidermis. The difference in amount and pattern of CD4, CD8 T-cells in the various compartments may be helpful in differentiating between psoriasis and psoriasiform lesions especially in cases with borderline morphology.

\section{REFERENCES}

1. Prasad PVS, Bikku B, Kaviarasan PK, Senthilnathan A: A clinical study of psoriatic arthropathy . Indian J Dermatol Venereol Leprol. 1997;73:166-70.

2. Lever WF: Non infectious erythematous, popular and squamous diseases. In David Elder MB, editor. Levers Histopathology of skin 8th ed. Philadelphia (USA): Lipincott William and W ilkins; 2005.p.183-91.

3. Cooper KD: Psoriasis: Leucocytes \& cytokines. Dermatol Clin. 1990;8:737.

4. Nikaein A, Morris L, Phiilips C: Characterisation of T-cell clones generated from skin of patients with psoriasis. J Am Acad Dermatol. 1993;28:551.

5. Gudjonsson JE, Johnston A, Sigmundsdottir H, Valdimarsson H: Immunopathogenic mechanism in psoriasis. Clin Exp Immunol. 2004; $135: 1-8$.

6. Tetsuya K, Hong D, Kazunori U, Mastutaka F: In situ localisation of IFN- $\Upsilon$ positive cells in psoriatic lesional epidermis. Eur $\mathrm{J}$ Dermatol. 2002;12:20-3.

7. Rho NK, Kim WS, Lee DY, Lee JH, Lee ES, Yang JM: Immunophenotyping of inflammatory cells in lesional skin of the extrinsic and intrinsic type of atopic dermatitis. Br J Dermatol. 2004; 151:119-25.

8. Pinkus $\mathrm{H}$, Mehregan AH: The primary histologic lesion of seborrheoic dermatitis and psoriasis. J Invest Dermatol. 1966;46:109-16.

9. Cabrijan L, Lipozencic J, Batinac T, Peternel S, Pastar Z: The role of CD4 and CS8 lymphocytes and macrophages in psoriasis vulgaris. Acta Dermatovenerol Croat. 2009;17:162-5.
10. Bata-Csorgo Z, Hammerberg C, Voorhees JJ, Cooper KD: Flowcytometric identification of proliferative subpopulations within normal human epidermis and the localisation of the primary hyperproliferative population in psoriasis. J Exp Med. 1993;178:1271-81.

11. Livden JK, Nilsen R, Bjerke JR, Matre R: In situ localisation of Interferon in psoriatic lesions. Arch Dermatol Res. 1989;281:392-7. 12. Bata-Csorgo Z, Hammerberg C, Voorhees JJ, CooperKD: Kinetics and regulation of human keratinocyte stem cell growth in short-term primary ex-vivo culture. Cooperative growth factor from psoriatic lesional $\mathrm{T}$ lymphocyte stimulates proliferation among psoriatic uninvolved, but not normal, stem keratinocyte. J Clin Invest. 1995;95:317-27.

13. Szabo SK, Hammerberg C, Yoshida Y, Bata-Csorgo Z, Cooper $\mathrm{KD}$ : Identification and quantitation of Interferon- $\Upsilon$ producing T-cells in psoriatic lesions: Localisation to both CD4 and CD8 subsets. J Invest Dermatol. 1998;111:1072-8.

14. Bovenschen HJ, Seyger MMB, Van De Kerkhof PCM: Plque psoriasis vs atopic dermatitis \& lichen planus: a comparison for lesional T-cell subsets, epidermal proliferation and differentiation. Br J Dermatol. 2005;153:72-8

15. Nickoloff BJ, Wrone-Smith T: Injection of pre-psoriatic skin CD4+T-cells induces psoriasis. Am J Pathol. 1999;155:145-58.

16. Tan JT, Ernst B, Kieper WC, LeRoy E, Sprent J, Surh CD: Inter leukin (IL-15) and IL-7 jointly regulate homeostatic proliferation of memory phenotype CD8+ cells but are not required for memory phenotype CD4+ cells. J Exp Med. 2002;195:1523-32.

17. Vollmers, Menssesen A, Prinz JC: Dominant lesional Tcell receptor rearrangement persist in relapsing psoriasis but are $\mathrm{J}$. Inwest Dermatol. 2001;117:296-301.

18. Sigmundsdottier H, Gudjonsson JE, Johnsdottier I, Ludviksson BR, Vladimarsson H: The frequency of CLA+ and CD8+ T-cells in the blood of psoriasis patients closely correlates with the severity of their disease. Clin Exp Immunol. 2001;126:365-9.

19. Valdimarsson H, Baker BS, Jonsdotter I: Psoriasis a Tcellmediated auto immune do. Immunol Today. 1995:16:145-9.

20. Deguchi M, Ohtani H, Sato E, Naito Y, Nagura H, Aiba S, et al: Prefarative activity of CD8(+) Tcells as an important due to analyze $\mathrm{T}$ cell mediated Infl. Dermatoses. Arch. Dermatol Res. 2001;293:442-7.

21. Bos JD, Zonneveld I, Das PK: The skin immune system (SIS): distribution and immunophenotype of lymphocyte subpopulations in normal human skin. J Invest Dermatol. 1987;88:569-73.

22. Kimber I, Dearman RJ: Alergic contact dermatitis: the cellular effectors. Contact Dermatitis. 2002;46:1-5.

23. Jones JL, Berth-Jones J, Fletcher A, Huthinson PE: Assessment of epidermal dendritic cell markers and T-lymphocytes in psoriasis. Pathol. 1994;174:77-82.

24. Leung DYM: Atopic dermatitis: The skin as a window into the pathogenesis of chronic allergic diseases. J Allergy Clin Immunol. 1995;96:302-18.

25. Cooper KD: Atopic dermatitis; Recent trends in pathogenesis and therapy. J Invest Dermatol. 1994;102:128-37.

26. Braun-Falco O, Heilgermeir GP, Lincke-Plewig $\mathrm{H}$ : Histopathological differential diagnosis of psoriasis vulgaris and seborrheic eczema of the scalp. Hautarzt. 1979;30:478-83.

27. Tengvall Linder M, Johansson C, Scheynius A, Wahlgren CF: Positive atopy patch test reactions to Pityrosporum orbiculare in atopic dermatitis patients. Clin Exp Allergy. 2000;30:122-31.

28. Yoshiike T, Aikawa Y, Wongwaisayawan H, Ogawa H: HLADR Antigen expression on Peripheral T-cell subsets in Pityriasis rosea and Herpes Zoster. Dermatologica. 1991;182:160-3.

Copyright by Safia Rana, et al. This is an open access article distributed under the terms of the Creative Commons Attribution License, which permits unrestricted use, distribution, and reproduction in any medium, provided the original author and source are credited. 